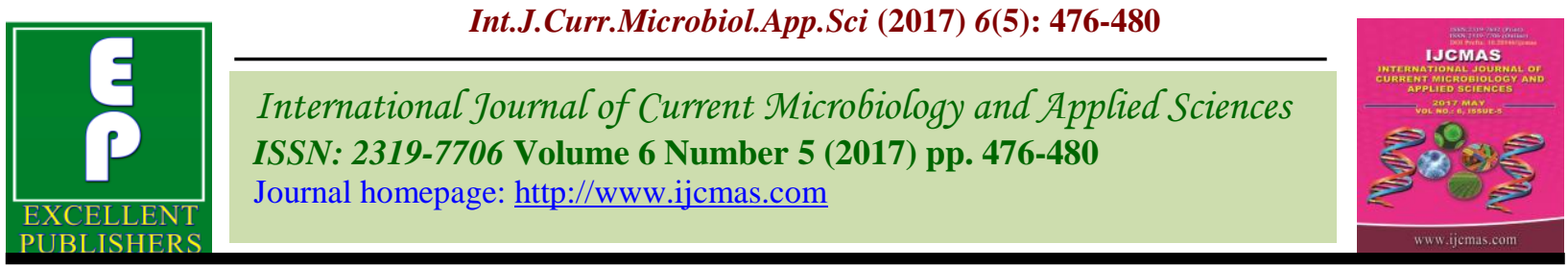

Original Research Article

https://doi.org/10.20546/ijcmas.2017.605.055

\title{
Evaluation of Endogenous Gene Validation: An Important Contrivance for Differential Gene Study in Pearl Millet
}

\author{
Poonam Kanani* and Y.M. Shukla \\ Department of Agricultural Biotechnology, Anand Agricultural University, \\ Anand-388 110, India \\ *Corresponding author
}

\begin{tabular}{|c|c|}
\hline & B S T R A C T \\
\hline & \multirow{6}{*}{$\begin{array}{l}\text { Nowadays selection and validation of endogenous gene is commonly being studied } \\
\text { worldwide for differential gene study. And it is also considered as inevitable for gene } \\
\text { validation studies. Endogenous gene expression varies profoundly with every cell and } \\
\text { tissue with even mere deviations at nominal levels too, thus a need of normalization. So } \\
\text { far, the most refined and steadfast method is preferably Quantitative Real-Time PCR } \\
\text { (qRT-PCR) for precise quantification of gene expression to understand explicit gene } \\
\text { functions at various development phases and beneath diverse environmental conditions } \\
\text { that plant encounters during its life. The data normalization to find most stable gene are } \\
\text { obtained through different software programs, such as geNorm, Norm finder and Best } \\
\text { keeper. Pearl millet [Pennisetum glaucum (L.) } R \text {. Br.] a major grain and forage crop, } \\
\text { frequently encounter various stresses both biotic and abiotic, and therefore more chances } \\
\text { of studying genes responsible for stress adaption. Thus insight into evaluation of } \\
\text { endogenous gene (such as actin, tubulin, GAPDH, ubiquitin etc.) validation studies can } \\
\text { prove to target more exact molecular mechanism for stress tolerance. }\end{array}$} \\
\hline & \\
\hline & \\
\hline $\begin{array}{l}\text { gene expression, } \\
\text { validation, } \\
\text { endogenous gene. }\end{array}$ & \\
\hline Article Info & \\
\hline $\begin{array}{l}\text { Accepted: } \\
04 \text { April } 2017 \\
\text { Available Online: } \\
10 \text { May } 2017\end{array}$ & \\
\hline
\end{tabular}

\section{Introduction}

Pearl millet (Pennisetum glaucum L.) is a monocot, diploid $(2 \mathrm{n}=2 \mathrm{x}=14)$ cereal crop plant belongs to family Poaceae, sub family Penicedae, also known as bajra. It is one of most important cereals growing worldwide in tropical semi arid regions mainly as food and forage crop in Africa and Asia, and It is the sixth most important crop after rice, wheat, maize, barley and sorghum, nutritionally rich in zinc, iron, and high antioxidants. It has haploid genome size of $2450 \mathrm{Mbp}$ and has DNA content of $1 \mathrm{C}=2.36 \mathrm{pg}$. (Budak et al., 2003, Malik, 2015). Plants being sessile in nature are enforced to face different environmental conditions in time course of their life span. The stresses such as drought, salinity and temperature: heat or cold are major abiotic and biotic stresses Biotic stress include four major diseases are downy mildew (Sclerospora graminicola), ergot (Claviceps fusiformis), smut (Tolysporium penicillariae) and rust (Puccinia substriata var. indica) which develop depending on the weather conditions and genotype are serious restraint for growth and productivity of pearlmillet (Neya and Kabore, 1987; Thakur et al., 2008).

All the processes related to physiological, morphological and biochemical changes are 
outright affected by changes in abiotic and biotic environmental interactions. Morphological symptoms leads to lower seed germination, decreased seedling growth and reduced dry matter content (Munns et al., 1982; Hasegawa, 2000). Wherein there are series of changes in physiological an biochemical changes occur which comprises elevated production of Osmoprotectant (such as proline, glycine betain and free amino acid), increased activity of antioxidant enzymes (Peroxidase, Catalase, Superoxide dismutase, Ascorbate Peroxidase, Polyphenol oxidase and etc.) (Alscher, 2002; Hasegawa, 2000).

\section{Endogenous genes}

Gene expression profiling represents an elating tool to divulge mechanisms implicated in the response of plants to environmental stress proving as one of the modern molecular biology technique cornerstones. It has provided insight into identification of hundreds of genes induced when plants under stress and helped in understanding of complex biological process, signaling and metabolic pathways (Kreps et al., 2002; Mantri et al., 2007 and VanGuilder et al., 2008). Real-time reverse transcription PCR (real-time RTPCR) is presently a standard method for precise expression profiling for selected gene study, it is highly specific and sensitive and had broader quantification range than former molecular techniques.

For precise and unwavering gene expression results, real time PCR normalized data is required alongside a control gene, which exhibits a highly uniform expression during various developmental phases and underneath different environmental conditions (VanGuilder et al., 2008). As the expression of endogenous gene is always steady in diverse conditions and they code for essential proteins constantly required by cell, these genes are referred as constitutively expressed, housekeeping, endogenous, reference or internal control genes (Stephen et al., 2001). Thus, a constant expression of these genes is a prerequisite, used for normalization in realtime PCR analysis, otherwise, erroneous results. Basically housekeeping genes which are involved in primary cellular processes are $\beta$-tubulin (Tub), Actin (ACT), I8S rRNA, Glyceraldehyde-3-phosphate dehydrogenase $(G A P D H)$, and Ubiquitin $(U b q)$ used earlier, with the idea to have uniform expression. But on contrary, reports illustrates that the transcript levels of these genes also vary significantly under different experimental conditions and are therefore not suitable for gene expression studies. So, therefore it is very important to investigate the stability of expression of commonly used endogenous genes in more depth and to identify novel and superior endogenous genes (Czechowski et al., 2005 and Thellin et al., 1999).

\section{Characteristics of endogenous genes as reference gene}

Single (or low) and known copy number

Low allelic variation in cultivars

Species specificity

Ubiquitously expressed in all tissues

Expression level remains at a steady state as compared to target gene expression.

Gene length of endogenous genes tends to be significantly more compact, shorter and with more exons than tissue specific genes. Scaffold/Matrix Attachment Regions (S/MAR) are less upstream of endogenous gene and poly (dA - dT) and (CCGNN) n found to be more abundant upstream of endogenous genes, as compared to tissue specific gene. They destabilize the formation of nucleosomes, leaving the DNA less packaged and maintaining constitutive gene expression (Davis et al., 2002). 
Modification of endogenous gene is done by homologous recombination-dependent gene targeting and chimeric RNA/DNA oligonuclieotide - directed gene targeting to generate a site-specific base conversion, and homologous recombination-dependent gene targeting to produce either a base change or a gene replacement in a sequence-specific manner (Iida and Terada, 2005).

\section{Methods}

There are different approaches to study endogenous genes are northern blot, southern blot, slot or dot blot, semi and fully quantitative PCRs, microarray and real time PCR. Real time PCR is being in wide use. The procedure follows as:

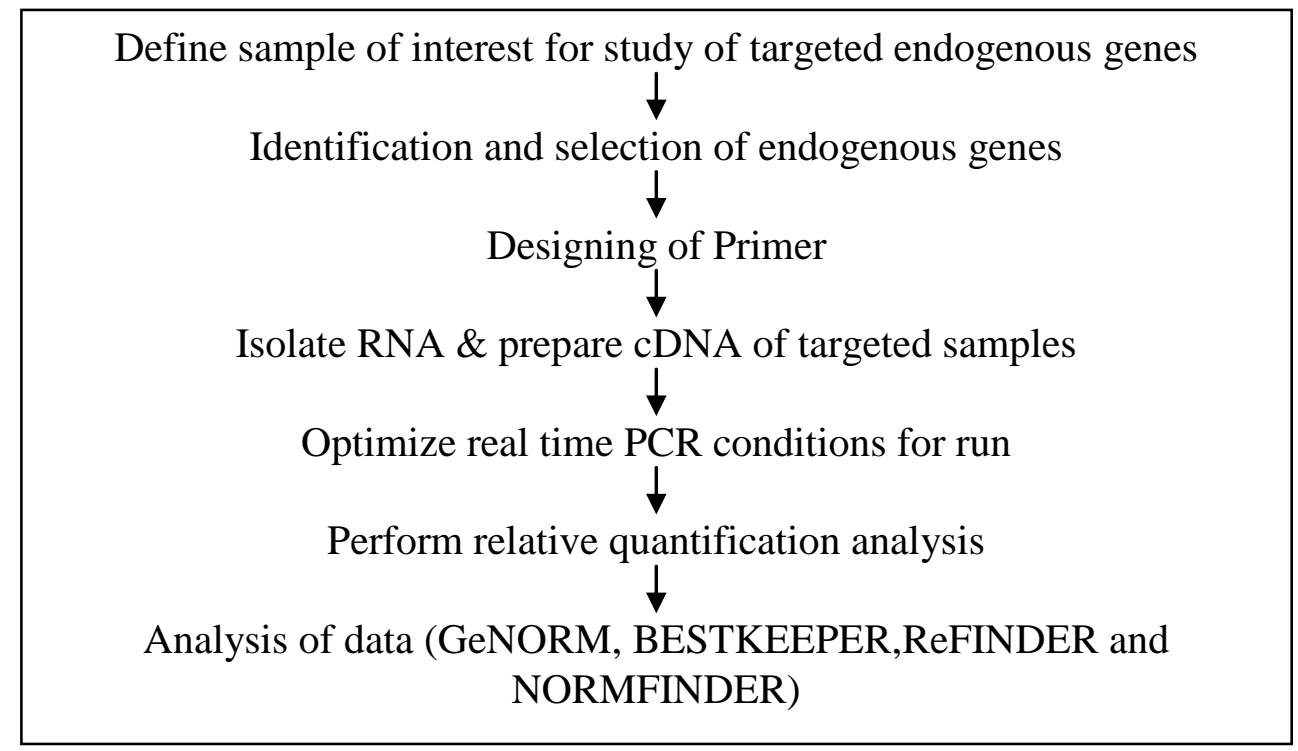

Validation of endogenous genes in pearl millet under various biotic and abiotic stresses

Pearl millet is well cultivated in semi-arid climates, so there is more likelihood of having huge number of stress alleviating genes that helps for stress adaptation. As little availability of genome sequence information in pearl millet, has constrained the advancement in gene annotation, discovery, characterization, transcript profiling and in further crop developmental programs. Analysis of genes by by qRT-PCR in pearl millet is restricted due to short of sequence information available till now, which can be provided as suitable reference genes. Therefore identification and selection of suitable reference gene remain to be a pre requisite for future gene expression studies in pearl millet and other allied species of millet (Reddy et al., 2015). With advancement and more focus on studies in pearl millet, few scientists are engrossed for screening endogenous genes in various biotic and abiotic stress condition.

\section{Primer selection}

Due to inadequate accessibility of sequence information of pearlmillet in the NCBI GenBank and EBI, therefore different approaches were carried out for sequence information retrieval. EST database was used for retrieving of the sequences and degenerate primers were designed based on the homologous genes of other closely related plant species (Reddy et al., 2015). Like 
GenBank accession numbers of selected candidate reference genes from Arabidopsis and rice prior were used for study, also by searching locus IDs and/or GenBank accession numbers of foxtail millet (a close relative of pearlmillet) orthologous locus Ids from Phytozome v.9.0., Sequences (Saha and Blumwald, 2014; Shivhare and Lata, 2016).

Few studies on Pearl millet endogenous gene validation selection integrated both traditional housekeeping as well as several new reference genes. Saha and Blumwald, 2014 assessed about 18 candidate reference genes namely Actin (ACT), Glyceraldehyde-3Phosphate Dehydrogenase (GAPDH), Cyclophilin $(C Y C)$, Phosphoenol Pyruvate Carboxylase-related Kinase $(P E P K R)$, F-Box domain containing protein $(F B X), \alpha$ Tubulin (TUA), Eukaryotic Elongation Factor 1 alpha (eEFla), Eukaryotic Initiation Factor 4a2 (eIF4a2), Protein Phosphatase 2A (PP2A), Rubisco Activase (RCA), S-Adenosyl Methionine Decarbox ylase $(S A M D c)$, Tonoplast Intrinsic Protein (TIP41), Ubiquitin-Conjugating Enzyme 2 (UBC2), Ubiquitin-Conjugating Enzyme 18(UBC18), Transmembrane Protein 56(UNK), Ubiquitin 5 (UBQ5), 18S Ribosomal RNA (18S rRNA) and 25S Ribosomal RNA (25S rRNA) in 234 samples (three important pearl millet genotype). Analyses of $\mathrm{Ct}$ values via BestKeeper, Stability Index, Norm finder, DCt, ge Norm and Ref Finder programs ranked PP2A, TIP41, UBC2, UBQ5 and ACT as the most reliable endogenous genes for normalization study under different experimental condition. Reddy et al., 2015 reported 11 endogenous genes Protein Phosphatase 2C $(P P 2 C)$, UbiquitinConjugating Enzyme $(U B C)$, Malate Dehydrogenase $(M D H), \beta$-tubulin $(\beta-T U B)$, Glyceraldeyde-3-Phosphate Dehydrogenase $(G A P D H)$, Elongation Factor 1-alpha $(E F-$ $1 \alpha)$, Eukaryotic Initiation Factor 4A (EIF4A), $\beta$-Actin $(\beta A C T)$, Acyl Carrier Protein $(A C P)$,
CYP Cyclophilin (CYP) and Ribosomal Protein $(S 2440 S)$. Result showed that $E F-1 \alpha$ and EIF4A expression was most stable indifferent plant tissues, $M D H$ and EIF4A were found to be stable under different abiotic stress conditions. In the midst of the different genotypes of pearl millet evaluated, while $U B C$ and $M D H$ genes showed most stable expression, $M D H$ and $A C P$ showed superior stability in all samples set. Shivhare and Lata, 2016 illustrated 10 potential internal control genes viz. Actin (ACT), Elongation Factor $1 \alpha$ $(E F-1 \alpha)$, Malate Dehydrogenase $(M D H)$, Eukaryotic Initiation Factor 4A (eIF4A), Heat shock protein 90 (HSP90), Ribosomal Protein L20 (RPL20), Glutaredoxin (GlutR), Protein Phosphatase 2A (PP2A), UbiquitinConjugating Enzyme E2 (UBC-E2) and Tonoplast intrinsic protein $41(T I P 41)$ in various developmental tissues and different individual abiotic stresses and also their combinations at $1 \mathrm{~h}$ (early) and $24 \mathrm{~h}$ (late) of stress using Norm Finder, geNorm and RefFinder algorithms. Data analysis revealed that $E F-1 \alpha$ and $U B C-E 2$ was best internal control genes across all samples.

In conclusion, in this present paper, it is tried to show the importance of validating endogenous genes in pearl millet for further differential gene expression studies is must for precise and accurate data obtaining. Profoundly different case studies reviewed so far showed the variability in expression levels at minor levels among endogenous genes. Thus it is demand of gene expression studies based on real time PCR to start with appropriate selection and validation of endogenous genes at even single experimental condition.

\section{References}

Budak, H., Pedraza, F., Cregan, P.B., Beaenziger, P.S. and Dweikat, I. 2003. Development and utilization of SSR to estimate the degree of genetic 
relationships in a collection of pearl millet germplasm. Crop Sci., 43: 2284-2290.

Malik, S. 2015. Pearl millet-nutritional value and medicinal uses, Ijariie., 1(3):414-418.

Neya, A., and Kabore, K.B. 1987. Evaluating the increase of Anthracnose and red stalk rot caused by colletotrichum graminicola on Sorghum. Phytoprotection, 68: 121126

Thakur, R.P., Rai, K.N., Khairwal, I.S. and Mahala, R.S. 2008. Strategy for downy mildew resistance breeding in pearl millet in India. ejournal.icrisat. org, 6.

Munns, R., Greenway, H., Delane, R. and Gibbs, J. 1982. Ion concentration and carbohydrate status of the elongating leaf tissue of Hordeum vulgare growing at high external $\mathrm{NaCl}$ causes of the growth reduction. J. Exp. Bot., 33: 574-583.

Hasegawa, P.M., Bressan, R.A., Zhu, J.K. and Bohnert, H.J. 2000. Plant cellular and molecular responses to high salinity. $A$. Rev. of Plnt Physiol. and Plnt Mol. Bio., 51: 463-499.

Kreps, J.A., Wu, Y., Chang, H., Zhu, T., Wang, $\mathrm{X}$. and Harper, J. 2002. Transcriptome changes for Arabidopsis in response to salt, osmotic, and cold stress. Plant Physiol., 130: 2129-2141.

Mantri, N., Ford, R., Coram, T., and Pang, E. 2007. Transcriptional profiling of chickpea genes differentially regulated in response to high-salinity, cold and drought. BMC Genomics, 8: 303.

VanGuilder, H.D., Vrana, K.E. and Freeman, W.M. 2008. Twenty-five years of quantitative PCR for gene expression analysis. BioTechniques, 44: 619-626.

Stephen, R., Sturzenbaum and Peter, K. 2001. Control genes in quantitative molecular biological techniques. Biochem. Physiol.
Part B 130: 281- 289.

Thellin, O., Zorzi, W., Lakaye, B., Borman, B., Coumans, B., Hennen, G., Grisar, T., Igout, A. and Heinen, E. 1999. Housekeeping genes as internal standards: use and limits. J. Biotechnol., 75: 291295.

Czechowski, T., Stitt, M., Altmann, T., Udvardi, M. and Scheibl,e W. 2005. Genome-wide identification and testing of superior reference genes for transcript normalization in Arabidopsis. Plant Physiol., 139: 5-17.

Davis, C.I., Mekhedov, S.L., Hartl, D.L., Koonin, E.V. and Kondrashov, F.A. 2002. Selection for short introns in highly expressed genes. Nat. Genet., 31: 415418.

Iida, S. and Terada, R. 2005. Modification of endogenous natural genes by gene targeting in rice and other higher plants. Plant Mol. Biol., 59: 205-219.

Reddy, P.S., Reddy, D.S., Sharma, K.K., Mathur, P.B., and Vadez, V. 2015. Cloning and validation of reference genes for normalization of gene expression studies in pearl millet [Pennisetum glaucum(L.) R. Br.] by quantitative realtime PCR. Plant Gene, 1: 35-42.

Shivhare, R. and Lata, C. 2016. Selection of suitable reference genes for assessing gene expression in pearl millet under different abiotic stresses and their combinations. Scientific reports, 6:23036

Saha, R. and Blumwald, E. 2014. Assessing Reference Genes for Accurate Transcript Normalization Using Quantitative RealTime PCR in Pearl Millet [Pennisetum glaucum (L.) R. Br.]. PLOS ONE, 9(8): e106308.

\section{How to cite this article:}

Poonam Kanani and Shukla, Y.M. 2017. Evaluation of Endogenous Gene Validation: An Important Contrivance for Differential Gene Study in Pearl Millet. Int.J.Curr.Microbiol.App.Sci. 6(5): 476-480. doi: https://doi.org/10.20546/ijcmas.2017.605.055 